\title{
Research on Evaluation System of Investment Benefit of Power Equipment Overhaul Based on Reliability Theory
}

\author{
Yuanhui Huang ${ }^{1}$, Dunnan $\mathrm{Liu}^{2}$, Xiaokui $\mathrm{Su}^{3}$ and Luqing $\mathrm{Liu}^{4}$ \\ ${ }^{1}$ Zhongshan power supply bureau, Zhongshan City, P. R. China \\ ${ }^{2}$ North China Electric Power University, Beijing City, P. R. China \\ ${ }^{3}$ Zhongshan power supply bureau, Zhongshan City, P. R. China \\ ${ }^{4}$ North China Electric Power University, Beijing City, P. R. China \\ ${ }^{*}$ Corresponding author
}

\begin{abstract}
In view of the lack of reliability theory in the evaluation of investment efficiency of power equipment overhaul, this paper presents a reliability evaluation system based on reliability theory for investment in power equipment overhaul. Based on the reliability optimization theory, this paper studies the relationship between reliability cost and benefit, and analyzes the reliability of power transmission equipment and reliability of the system. And the theory of reliability is applied to the evaluation of the investment benefit of the technical equipment overhaul.
\end{abstract}

Keywords- reliability theory; power equipment overhaul; benefit evaluation

\section{INTRODUCTION}

With China's economic development and improvement of people's living standards, increasing demand for electricity, building a strong and reliable power grid is critical. In order to serve China's economic development, should continue to increase and optimize the power equipment investment capital investment, accelerate the pace of power grid construction. However, electric power equipment investment projects are usually large-scale, complex technology, changing construction environment, from planning and design to put into operation, involving a large amount of investment. In addition, with the deepening of power market reform and the intensification of competition among power enterprises, power grid enterprises will face enormous competition and challenges. The low investment efficiency can not meet the requirements of the state and society for power grid enterprises.

In recent years, the power companies in the compression of fixed assets investment, the rate of return on assets is increasingly stringent assessment of the net, not to run the equipment in principle can not be modified, while the power company operating equipment reliability requirements are increasing, Equipment repair and repair strategy, without modification, through the repair work to improve the reliability of equipment operation and operating life (that is, the impact of the operation and maintenance costs).

In this paper, the reliability and cost-effectiveness of power equipment are researched based on the technical renovation of the electric power equipment of the power company. The reliability and optimization technology are integrated into one, and the optimal technical economic index is designed under the premise of reasonable and reliable Program, the establishment of the reliability theory based on the power equipment renovation project investment in comprehensive evaluation of the comprehensive evaluation index system [1-3].

\section{Reliability Evaluation of Power EQuipMent [4-} 7]

In the power system reliability analysis practice, the equipment and the system state stochastic change process needs to use the probability theory method to carry on the description and the processing. Therefore, in order to accurately analyze the reliability of equipment and systems, the various departments of the power system must carry out long-term statistics on the historical operation data of various equipment and process the historical data into data which can reflect the reliability level of the equipment. The reliability feature vectors are as follows:

\section{A. Equipment Failure Rate $\lambda(\mathrm{t})$}

Assuming that the device has been operating at time $t$, then the equipment after $\mathrm{t}$ in the $4 \mathrm{t}$ small time fault conditional probability density is defined as the failure rate of the device, the formula is

$$
\lambda(\mathrm{t})=\lim _{\Delta t \rightarrow 0} \frac{1}{\Delta t} P\left[\mathrm{t}<\mathrm{T}_{\mathrm{u}}<\mathrm{t}+\Delta t \mid \mathrm{T}_{\mathrm{u}}>t\right]
$$

The smaller the failure rate of a device $\lambda(\mathrm{t})$, the smaller the probability that the device $[\mathrm{t}, \mathrm{t}+\Delta \mathrm{t}]$ will fail in the time interval, and vice versa. The statistical data shows that the typical relationship between the failure rate and the time of the equipment during the whole life of the repairable equipment is shown in Fig 1. 


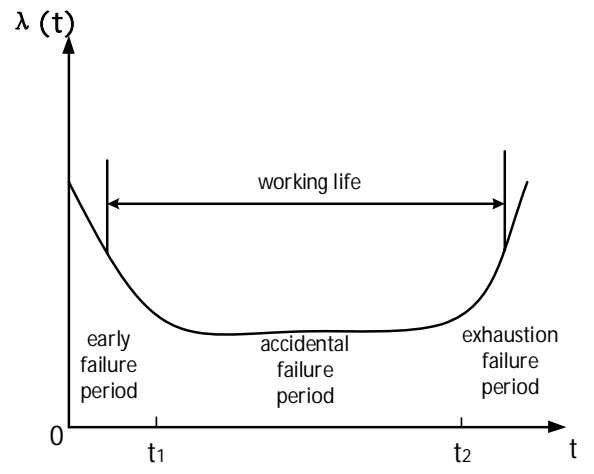

FIGURE I. EQUIPMENT FAILURE RATE CURVE (BATHTUB CURVE)

Curve similar to the tub, it is also known as bathtub curve. According to the life of repairable equipment, the failure rate can be divided into three stages: the first stage is called the early failure period, the corresponding time $0 \sim \mathrm{t} 1$, is due to design, manufacturing and assembly defects and unskilled operators caused equipment failure The second stage is due to accidental causes (such as bird damage, lightning, equipment components failure, misuse, etc.) caused by the fault of the occasional failure period, corresponding to the time period $\mathrm{t} 1 \sim \mathrm{t} 2$, this time, this failure rate is relatively high; The failure rate is almost constant during the period, which is similar to a straight line parallel to the time axis, the value is smaller; the third stage is due to the aging of equipment components, fatigue and wear into the wear and tear failure period, failure rate increases with time, Corresponding to the period of time $\mathrm{t} 2 \sim \infty$.

When the equipment failure rate is constant, can be obtained according to the following formula

$$
\lambda=\frac{\text { Equipment failure frequency }}{\text { The total time of the device running }}
$$

\section{B. Equipment Reliability $R(t)$}

The definition of equipment reliability is:

$$
R(\mathrm{t})=\mathrm{P}\left[\mathrm{T}_{\mathrm{U}}>t\right]
$$

I.e. the probability that the actual working time is greater than the predetermined working time. When the equipment failure rate is constant, the device reliability can be deduced as:

$$
R(\mathrm{t})=e^{-\lambda t}
$$

\section{Equipment Repair Rate $\mu(t)$}

Equipment repair rate indicates the degree of difficulty and effect of repairable equipment repairs, usually expressed as $\mathrm{u}(\mathrm{t})$. It is defined as: the device is not repaired before time $\mathrm{t}$, and the conditional probability density of the condition that is repaired after a small time $t$ is expressed as:

$$
\mu(\mathrm{t})=\lim _{\Delta t \rightarrow 0} \frac{1}{\Delta t} P\left[\mathrm{t}<\mathrm{T}_{\mathrm{D}}+\mathrm{t}+\Delta t \mid \mathrm{T}_{\mathrm{D}}>t\right]
$$

According to some statistics, the repair time of the overhead line can be seen as an exponential distribution, while the buried cable repair time is closer to the normal distribution. Other equipment such as power transformers, switching equipment also has a similar situation. However, if these different types of distribution probabilities are calculated, the reliability prediction evaluation work will be greatly complicated. Taking into account the statistical method to obtain the reliability of the equipment itself may be greater error, so in practice, all the repairable equipment will be regarded as an exponential distribution are calculated. General repair rate is constant, commonly used

When the equipment repair rate is constant, the formula is as follows:

$$
\mu=\frac{\text { The number of times the device is repaired }}{\text { Total equipment maintenance time }}
$$

\section{Mean Time To Failure (MTTF) and Mean Time To Repair (MTTR) of Equipment}

When the equipment failure rate is constant and the repair rate is constant, the mean time to fail (MTTF) and mean time to repair MTTR (Mean Time to Repair) are also constant. They are the failure rate and repair The reciprocal of the rate

$$
M T T F=\frac{1}{\lambda}
$$

$$
\operatorname{MTTR}=\frac{1}{\mu}
$$

\section{RELIABILITY EVALUATION OF POWER TRANSMISSION FACILITIES AND SYSTEMS [8-9]}

\section{A. Power Transmission and Distribution Facilities Reliability Statistical Evaluation}

The statistical evaluation of reliability of power transmission and transformation facilities refers to the facility-oriented reliability statistical evaluation aiming at facility function. The statistical indicators are in-depth grasp of power transmission and transformation facilities in the power system operation status of the main means: First of all, the power transmission facilities can be used to quantify the description: Second, the planning and design, equipment manufacturing, installation, production operation, maintenance, Production management and other aspects of the overall level of measurement; again is to measure the 
technical conditions of power transmission and distribution facilities and the development of the reliability of the power system based on the criteria.

\section{B. Evaluation of Power Transmission and Transformation Facilities}

For the power transmission and transformation facilities which are included in the statistics, the statistical evaluation indexes of their reliability can be divided into time-type indicators such as available coefficient, operation coefficient, planned outage coefficient, forced outage coefficient, etc.; number of indicators such as planned outage rat, Unplanned outages, forced outages, and planned outages.

- Availability factor (AF)

Available Coefficient refers to the ratio of the number of hours available in the power transmission and transformation facilities to the number of hours during the statistical period. Reflecting the availability of power transmission facilities, the formula is

$$
A F=\frac{A H}{P H} \times 100 \%
$$

Assuming that one facility has 87.6 hours of service in one year $(8760 \mathrm{~h}), 8760$ hours of statistical time and 8672.4 hours of available hours, the facility's annual availability factor is $99 \%$.

- $\quad$ Planned outage rate (POR)

The planned outage rate refers to the ratio of the number of planned outage of power transmission and transformation facilities to the number of years (period) of statistical stations during the statistical period, which reflects the probability of planned outage of power transmission and transformation facilities.

$$
\mathrm{POR}=\frac{P O T}{U Y}
$$

Suppose a facility in the 1-year plan to stop two times, the statistical time is 1 year, the annual planned outage rate of 2 times per year.

- Unplanned outage rate (UOR)

Unscheduled outage refers to the ratio of the number of unscheduled outages to the number of years (STA) in the statistical period during the statistical period.

Reflecting the power transmission facilities, the probability of unplanned outages, the formula is

$$
U O R=\frac{U O T}{U Y}
$$

Suppose a facility is unplanned outage twice a year for one year, with a one-year statistic time and two unplanned outages per year.

- $\quad$ Forced outage rate (FOR)
Forced outage refers to the ratio of the number of forced outages to the number of years in the statistical period during the statistical period. Reflecting the power transmission and transformation facilities, the number of forced outage probability, the formula is

$$
F O R=\frac{F O T}{U Y}
$$

Suppose a facility in a year to force outage 1, the statistical time is 1 year, the annual forced outage rate of 1 times per year.

- Repeat the planned outage rate

Repetitive rate of outage refers to the ratio of planned outages between the number of planned outages during the statistical period and the number of years of planned outage facilities, with the number of planned outages scheduled for outage in the statistical period 2 or more planned outages Minus 1.

The formula is

\section{Repeat planned shutdown rate $=$} Repeat planned power outages

\section{The statistics platform for the planned power outage}

Suppose a facility is planned to be out of service three times in a year, twice a planned outage, for a one-year statistic and twice the annual planned outage rate.

In view of the power transmission facilities reliability evaluation index is more, in this no longer enumerate.

\section{ELECTRICAL EQUIPMENT REPAIR, TECHNICAL COMPREHENSIVE EVALUATION OF PROJECT INVESTMENT BENEFIT}

\section{A. Reliability Cost-Benefit Analysis [11]}

\section{(1) Define}

Power system reliability cost can be defined as the investment cost and operation cost that power enterprise needs to increase power supply reliability level to reach certain level of power supply system. Reliability benefit is defined as: the power system to achieve a certain level of reliability of the power supply to reduce the user to reduce power outages, that is, the benefits. Because the reliability of the corresponding level of socio-economic benefits is difficult to estimate, so often the reliability of the cost of electricity costs, that is, due to lack of electricity supply or interruption caused by Sichuan power shortage, power outage caused by economic losses to that. In this way, the reliability of cost and efficiency can be unified in the grid on the economy to measure for the power system to facilitate power planning. The cost-benefit analysis curve of reliability of power system, electric equipment and so on is shown in Fig 2. 


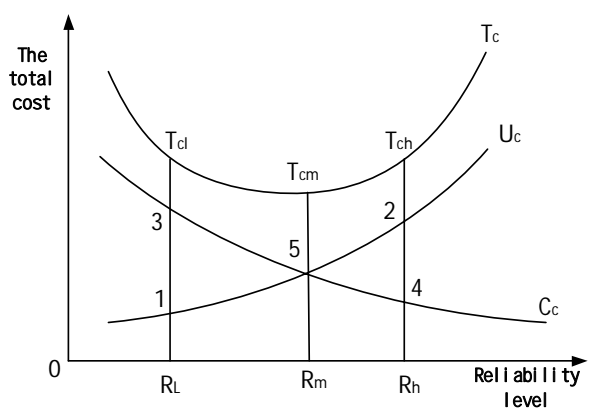

FIGURE II. RELIABILITY COST-BENEFIT ANALYSIS CURVE

The formula is:

$$
T_{C}=U_{C}+C_{C}
$$

Where: the cost of investment for the reliability (that is, the cost of enhanced measures, such as additional lines, the use of high-performance electrical equipment, etc.) curve; for the power loss curve for the reliability of the total cost curve.

(2) Reliability cost-benefit analysis

Reliability Cost-benefit analysis can be explained by the marginal cost and marginal benefit concept. Reliability Marginal cost is defined as an increase in the investment cost of a unit reliability level. Reliability Marginal benefit is defined as the cost of power loss resulting from an increase in the level of reliability of a unit or reduction in power cost. For marginal power shortage costs. The reliability costbenefit analysis curve is shown in Fig 3.

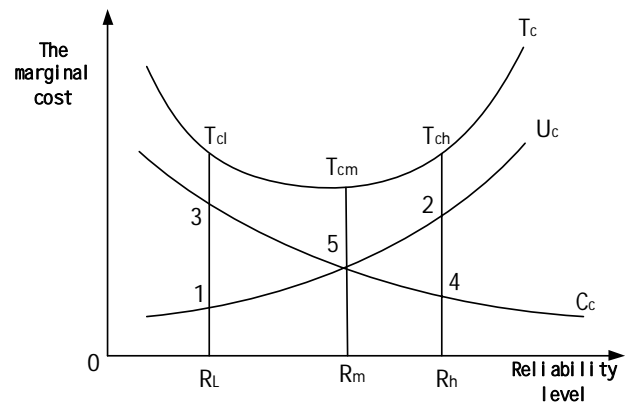

FIGURE III. RELIABILITY COST-BENEFIT ANALYSIS CURVE

Among them: $U_{C}$ - Reliability marginal cost curve;

$T_{C}$ - marginal supply total cost curve;

$C_{C}$-Reliability Marginal Efficiency Curve or Marginal Power Cost Curve.

From the analysis of Fig. 4, when the marginal cost of reliability equals to the marginal benefit of reliability, ie the curve $U_{C}$ and $C_{C}$ intersection, the total marginal cost of electricity supply is the lowest. The corresponding reliability level $R_{m}$ at this time is the optimum reliability level. If the grid investment is insufficient, and the reliability cost corresponds to 1 point on the curve $U_{C}$, the corresponding power supply reliability level $R_{1}$ is lower than that $R_{m}$, resulting in the marginal cost of the total power supply $T_{c 1}$ is higher than $T_{c m}$; if the grid investment is too high, the reliability cost corresponds to $U_{C} 2$ Point, although the corresponding power supply reliability level $R_{h}$ is higher than $R_{m}$. But the total cost of marginal power supply $T_{c h}$ is still higher than $T_{c m}$. Therefore, only when the investment cost per unit power supply reliability level equals the benefit (or the cost of power shortage) that the user obtains due to the increase of the reliability (14), the marginal power supply of the grid The lowest cost, at this time the level of reliability of the grid is the most reasonable.

$$
\frac{\partial B}{\partial R} \times \frac{\partial R}{\partial C}=1
$$

Where: $\mathrm{B}$ is the user to obtain the benefits; $\mathrm{R}$ is the level of reliability; $\mathrm{C}$ is the investment cost.

\section{B. Based on the Reliability Theory of Electrical Equipment Overhaul of Technical Transformation Project \\ Comprehensive Evaluation of Investment Returns}

Based on the reliability theory, the investment benefit of the technical renovation project of power equipment mainly includes economic benefit and social benefit. The economic benefit mainly includes investment return and unit cost. The social benefit includes the development of social economy and social environment And the natural environment.

TABLE I. INDICATOR SYSTEM OF ECONOMIC EFFICIENCY

\begin{tabular}{|c|c|}
\hline $\begin{array}{c}\text { Primary impact assessment } \\
\text { indicators }\end{array}$ & $\begin{array}{c}\text { Secondary impact assessment } \\
\text { indicators }\end{array}$ \\
\hline \multirow{2}{*}{ return of investment } & Dynamic ROI \\
\hline & internal rate of return \\
\hline \multirow{2}{*}{$\begin{array}{l}\text { marginal efficiency of } \\
\text { investment }\end{array}$} & $\begin{array}{l}\text { The cost reduction of unit } \\
\text { investment }\end{array}$ \\
\hline & $\begin{array}{l}\text { The reliability rate of the unit } \\
\text { investment }\end{array}$ \\
\hline
\end{tabular}
IMPACT EVALUATION OF THE PROJECT

TABLE II. INDICATOR SYSTEM OF SOCIAL IMPACT

\begin{tabular}{|c|c|}
\hline $\begin{array}{c}\text { Primary impact assessment } \\
\text { indicators }\end{array}$ & $\begin{array}{c}\text { Secondary impact assessment } \\
\text { indicators }\end{array}$ \\
\hline \multirow{4}{*}{$\begin{array}{l}\text { The impact on social and } \\
\text { economic development }\end{array}$} & Improve social employment \\
\hline & promoting industrial development \\
\hline & $\begin{array}{c}\text { improve the revenue of land } \\
\text { revenue }\end{array}$ \\
\hline & promote the economic development \\
\hline \multirow{2}{*}{$\begin{array}{l}\text { The impact of social } \\
\text { environment development }\end{array}$} & Provide grid operation efficiency \\
\hline & $\begin{array}{l}\text { Provide the living standard of the } \\
\text { residents }\end{array}$ \\
\hline \multirow{3}{*}{$\begin{array}{c}\text { The impact of nature } \\
\text { environment }\end{array}$} & environmental quality \\
\hline & pollution effect \\
\hline & natural disaster \\
\hline
\end{tabular}
EVALUATION OF THE PROJECT 


\section{CONCLUSION}

This paper makes full use of the data base of power equipment overhaul, according to the theory of reliability, the investment benefit evaluation of power equipment overhaul has been studied and the related index system has been established. This paper successfully validates the feasibility of the reliability theory in the field of investment benefit evaluation of power equipment overhaul and expands the application of reliability theory. However, there are still a lot of problems in the data mining of the index, and the reliability optimization should be solved urgently. In the future, we should consider further data mining and optimize the evaluation system to construct the deep evaluation system of the investment.

\section{REFERENCES}

[1] FENG Yongqing, ZHANG Boming, WU Wenchuan.Presentation and development of operational risk in power system operation based on credibility theory $[\mathrm{J}]$. Automation of Electric Power Systems, 2006,30 (01): 17-23.

[2] FENG Yong-qing, WU Wen-chuan, ZHANG Bo-ming, SUN Hongbin.Operation Risk Assessment of Power System Based on Credibility Theory Part Two Theoretical Basis [J]. Automation of Electric Power Systems, 2006,30 (02): 11-16.

[3] Application and engineering practice [J]. Automation of Electric Power Systems, 2006,30 (03): 11-14. [3] FENG Yong-qing, WU Wen-chuan, ZHANG Bo-ming, SUN Hong-bin.Evaluation of Operational Risk of Power System Based on Credibility Theory.

[4] Yang Jing, Xiang Xiaodong, Wu Gaoming, and so on. Application of Reliability Assignment Theory in System Security Objectives [J]. Chinese Journal of Safety Science, 2007, (12): 142-146,195.

[5] SUN Ping, ZHU Wei, XING Tao. Reliability Analysis of Urban Underground Pipeline System [J]. Journal of Safety Science and Technology of China, 2009,5 (4): 191-194.

[6] Peng Weigong, Zhou Jijun, Xiang Xiaodong, et al.Application of reliability theory in public safety field $[\mathrm{J}]$. Chinese Journal of Safety Science, 2009, (5): 16-20.

[7] Zeng Shengkui, Zhao Tingdi, Zhang Jianguo, and so on. System Reliability Design Analysis Course [M]. Beijing: Beijing University of Aeronautics and Astronautics Press, 2004.

[8] Billinton R. Composite system reliability evaluation [J]. Power Apparatus and Systems, IEEE Transactions on, 1969, 88 (4): 276-281.

[9] Guo Yongji. Power System Reliability Analysis [M]. Beijing: Tsinghua University Press, 2013.

[10] BAI Chao-hong, WANG Xi-fan.Passibility Assessment of Main Wiring of Pumped Storage Power Station [J]. Automation of Electric Power Systems, 2006, 30 (9): 9-14.

[11] DUAN Dong-li, WU Xiao-yue, DENG Hong-zhong.Evaluation of Distribution System Reliability Based on Time-varying Failure Rate and Service Recovery Time Model [J]. Proceeding of the CSEE, 2011,31 (28): 57-64. 